\title{
Adult Body Weights and Morphometric Traits of Ganjam Goats of Odisha and Prediction of Body Weights from Body Measurements
}

\author{
Dillip Kumar Karna ${ }^{1 *}$, Aditya Prasad Acharya ${ }^{2}$, Bhabesh Chandra Das ${ }^{3}$, Gangadhar Nayak ${ }^{1}$ and \\ M.R. Dibyadarshini ${ }^{1}$ \\ ${ }^{1}$ Department of Animal Breeding and Genetics, College of Veterinary Science and Animal Husbandry, Orissa University of \\ Agriculture and Technology, Odisha, INDIA \\ ${ }^{2}$ Department of Veterinary Pathology, College of Veterinary Science and Animal Husbandry, OUAT, Odisha, INDIA \\ ${ }^{3}$ Department of Veterinary \& Animal Husbandry Extension, College of Veterinary Science and Animal Husbandry, \\ OUAT, Odisha, INDIA \\ *Corresponding author: DK Karna; E-mail: dkarna@gmail.com
}

Received: 11 June, 2020

Revised: 18 Nov., 2020

Accepted: 22 Nov., 2020

\begin{abstract}
Present study was carried out in Chhatrapur, Rambha, Khallikote and Jirabadi clusters of All India Coordinated Research Project on goat improvement in Ganjam district of Odisha from 2015 to 2017 to study the body weight and measurements of Ganjam goats, their correlations, and predictability of the body weight from body measurements. Data on body weight (kg), body length $(\mathrm{cm})$, wither height $(\mathrm{cm})$ and chest girth $(\mathrm{cm})$ were recorded in adult Ganjam goats having one to four pairs of permanent incisor (PPI) teeth. Descriptive statistics and regression analyses were used. The mean body weight ranged from $22.5 \mathrm{~kg}$ to 30.6 $\mathrm{kg}$, mean body length ranged from 63.0 to $69.6 \mathrm{~cm}$, mean wither height ranged from 67.3 to $71.8 \mathrm{~cm}$ and mean chest girth ranged from 68.6 to $78.0 \mathrm{~cm}$. All the correlations were found to be positive, moderate to high in magnitude and statistically significant $(\mathrm{P}<0.01)$. All the predictive models developed with each of the three body measurements were found to be statistically highly significant $(\mathrm{P}<0.01)$. The best-fitted regression equations were $-23.68+0.29 * \mathrm{BL}+0.16 * \mathrm{WH}+0.25 * \mathrm{CG}$ for $1 \mathrm{PPI}$ age group, the equation: $-34.82+0.48 * \mathrm{BL}+0.42 * \mathrm{CG}$ for age group $2 \mathrm{PPI}$, the equation: $-28.13+0.47 * \mathrm{BL}+0.33 * \mathrm{CG}$ for age group 3 PPI and the equation: $-33.33+0.14 * \mathrm{BL}+0.18 * \mathrm{WH}+0.54 * \mathrm{CG}$ for 4 PPI age group. Chest girth was the dominant predictor variables among the three linear body measurements for all age groups except 1 PPI age group which had body length as the principal predictor.
\end{abstract}

\section{HIGHLIGHTS}

(0 Average body weight, body length, wither height and chest girth of adult Ganjam goats belonging to four age groups were estimated.

(0 Correlation analysis of the growth and morphometry was done.

( Chest girth was the most important predictor of live weight.

Keywords: Ganjam goats, Adult body weight, morphometry, prediction, regression

Goats produce meat, milk, manure, wool and other fibres and play an important role in the economy of poor and marginal farmers. Knowledge of body weight of goat is very important as not only the feedings of the goats are done on the basis their body weight, but also the dosages of medicines and other feed supplements are calculated on the basis of body weights. The major component of the output from goat is meat that constituted 13.53 percent of the total annual meat production in the year 2017-18 in India (Anonymous 2019). Body weight of the goat

How to cite this article: Karna, D.K., Acharya, A.P., Das, B.C., Nayak, G. and Dibyadarshini, M.R. (2020). Adult body weights and morphometric traits of Ganjam goats of Odisha and prediction of body weights from body measurements. J. Anim. Res., 10(6): 1029-1036.

Source of Support: None; Conflict of Interest: None क्ष 
is one of the most important economic characters that significantly determines the price of the goat. Accurate measurement of the body weight of goats is essential for fixing a sale price for it. As the poor and marginal farmers mostly rear goats, they often go for sale of their goats without correctly assessing the body weights. Several workers (Sharma and Das, 1995; Thiruvenkadan, 2005; Seifemichael et al., 2014; Berhe, 2017 and Hopker et al., 2019) have used body measurements to predict the live weight of goats by regressing the body weights on the body measurements in different breeds. Karna et al. (2020) developed regression equation for prediction of body weights from body measurements from growing Ganjam goats. However, such procedure is not available for adult Ganjam goats, which is one of the main recognised goat breeds of Odisha. The information available on the adult body weight and body measurements like body length, wither height and chest girth are scanty and based on fewer observations (Rao et al., 2009). Therefore, the present investigation was undertaken to study the adult body weight and measurements of Ganjam goats, their correlation, and predictability of the body weight from body measurements.

\section{MATERIALS AND METHODS}

\section{Area of study and flock details}

The study area comprised of four field clusters namely: Chhatrapur, Rambha, Khallikote and Jirabadi of All India Coordinated Research Project on goat improvement in the Ganjam District of Odisha located at $19.35^{\circ}-19.92^{\circ} \mathrm{N}$ and $84.98^{\circ}-85.12^{\circ} \mathrm{E}$. Ganjam district is the home tract of the Ganjam breed of goat which is the most important recognised goat breed of Odisha. Out of the four clusters, three cluster Chhatrapur, Rambha and Khallikote belong to the $4^{\text {th }}$ Agroclimatic zone i.e. East and the South Eastern coastal plane and experience relatively higher maximum and minimum temperature and lower rainfall as compared to the 4 th cluster which remains in the $5^{\text {th }}$ Agroclimatic zone of Odisha. The average maximum and minimum temperature experienced in these areas ranged from $37^{\circ} \mathrm{C}$ to $39^{\circ} \mathrm{C}$ and $10.8{ }^{\circ} \mathrm{C}$ to $11.5^{\circ} \mathrm{C}$ respectively. The mean annual rainfall ranged from $1577 \mathrm{~mm}$ to $1597 \mathrm{~mm}$ (Karna et al. 2020).

\section{Data collection}

Goats were entirely reared in extensive system by the poor and marginal farmers, majority of them belong to Golla communitity. The flock size of Ganjam goat ranged from 40 to 500 . The goats are mostly reared in range system. The farmers move along with their flocks in search of browsing material in most part of the years. Data on body weight $(\mathrm{kg})$, body length $(\mathrm{cm})$, wither height $(\mathrm{cm})$ and chest girth $(\mathrm{cm})$ were recorded on 1014 Ganjam goats during the period 2015 to 2017 . Out of the total goats, the males and females recorded were 329 and 685 respectively. The adult goats were those having one to four pairs of permanent incisor teeth.

The body weights (BW) of goats were recorded in $\mathrm{Kg}$ by using an electronic weighing scale with precision up to $100 \mathrm{~g}$. The linear body measurements were recorded using a measuring tape with graduation in centimetre. The body length (BL) was measured from the point of pin bone to point of shoulder. The wither height (WH) was measured as the distance from the ground level to the level of wither of the animal in standing position. The chest girth (CG) was measured by taking the measurement of circumference of the chest just behind the front leg with the animals in standing position as described by Karna et al. (2020).

\section{Statistical Analysis of data}

Data on weight and measurements were divided into four age group categories viz. one pair of permanent incisor (1 PPI), two pairs of permanent incisor (2 PPI), three pairs of permanent incisors (3 PPI) and four pair of permanent incisor (4 PPI). The descriptive statistics and regression analyses were carried out using SAS software package (version 9.3 for Windows) and graphics were produced using R software (version 4.0.0). The regression analysis was done with a single predictor first, then taking two predictor variables and then taking all three measurements. The best fitted regression equation was selected using step-wise regression method taking all the three predictors i.e. body length $(\mathrm{BL})$, wither height $(\mathrm{WH})$ and chest girth $(\mathrm{CG})$ to predict the body weight. The significance level kept for entry and to stay in the model was at 0.05 . The regression analysis was done for each age group separately. The Mean Absolute Error (MAE) and Mean Absolute Percentage Error (MAPE) were estimated for 
the best fitted regression equation for each age groups as described by Topal and Boulkbasi (2008).

\section{RESULTS AND DISCUSSION}

\section{Body weights and body measurements}

The basic statistics of body weight and measurements are presented in Table 1. The mean body weight of Ganjam goats ranged from $22.5 \mathrm{~kg}$ to $30.6 \mathrm{~kg}$ in adult Ganjam goats. The mean body length ranged from 63.0 to $69.6 \mathrm{~cm}$, mean wither height ranged from 67.3 to $71.8 \mathrm{~cm}$ and the mean chest girth ranged from 68.6 to $78.0 \mathrm{~cm}$. The distribution of body weights and the measurements are presented in Fig.1. The mean body weights and measurements of Ganjam goats in the present investigation at all the four age groups are lower than the reports made by Rao et al. (2009). Kuralkar et al. (2013) reported similar body dimensions of Berari goats of Maharashtra. Comparable body weights and measurements were also reported by Verma et al. (2009) in Malbari goats and Verma et al. (2010) in Sangamneri goats.

Table 1: Basic statistics of body weight (BW) in $\mathrm{kg}$, body length (BL) in $\mathrm{cm}$, wither height (WH) in $\mathrm{cm}$ and chest girth (CG) in $\mathrm{cm}$ for Age group 1 PPI to 4 PPI

\begin{tabular}{llllll}
\hline \multirow{2}{*}{ Traits } & \multirow{2}{*}{ Parameters } & \multicolumn{4}{c}{ Age groups } \\
\cline { 3 - 6 } & & $\mathbf{1}$ PPI & 2 PPI & 3 PPI & 4 PPI \\
\hline BW & Mean & 22.51 & 27.18 & 27.39 & 30.60 \\
& Std Dev & 4.31 & 4.53 & 4.07 & 4.85 \\
& N & 269 & 262 & 237 & 246 \\
BL & Mean & 63.06 & 66.28 & 67.67 & 69.68 \\
& Std Dev & 7.13 & 4.83 & 4.51 & 5.59 \\
& N & 269 & 262 & 237 & 246 \\
WH & Std Dev & 6.60 & 6.18 & 5.57 & 5.42 \\
& Mean & 67.32 & 68.74 & 70.36 & 71.87 \\
& N & 269 & 262 & 237 & 246 \\
CG & Mean & 68.67 & 71.99 & 71.82 & 76.03 \\
& Std Dev & 5.44 & 5.17 & 3.75 & 4.78 \\
& N & 269 & 262 & 237 & 246 \\
\hline
\end{tabular}

NB: Age group 1 PPI: one pair of permanent incisors, 2 PPI: two pair of permanent incisors, 3 PPI: three pair of permanent incisors and 4 PPI: four pair of permanent incisors.

\section{Relationship of Adult body weights with morphometry}

The Pearson's correlation coefficients of the body weight, body length, wither height and chest girth among themselves for all the age groups are presented in the Table 2.

Table 2: Age group-wise Correlation coefficients matrix of Body Weight and Measurements at age groups 1 PPI to 4 PPI

\begin{tabular}{lllll}
\hline $\begin{array}{l}\text { Age } \\
\text { Groups/ } \\
\text { traits }\end{array}$ & $\begin{array}{l}\text { Body Weight } \\
\text { (BW) }\end{array}$ & $\begin{array}{l}\text { Body Length } \\
\text { (BL) }\end{array}$ & $\begin{array}{l}\text { Wither } \\
\text { Height }\end{array}$ & $\begin{array}{l}\text { Chest } \\
\text { Girth } \\
\text { (CG) }\end{array}$ \\
\hline 1 PPI BW & 1.00 & 0.85 & 0.69 & 0.77 \\
BL & 0.85 & 1.00 & 0.61 & 0.70 \\
WH & 0.69 & 0.61 & 1.00 & 0.49 \\
CG & 0.77 & 0.70 & 0.49 & 1.00 \\
2 PPI BW & 1.00 & 0.76 & 0.36 & 0.77 \\
BL & 0.76 & 1.00 & 0.18 & 0.48 \\
WH & 0.36 & 0.18 & 1.00 & 0.44 \\
CG & 0.77 & 0.48 & 0.44 & 1.00 \\
3 PPI BW & 1.00 & 0.75 & 0.54 & 0.71 \\
BL & 0.75 & 1.00 & 0.56 & 0.56 \\
WH & 0.54 & 0.56 & 1.00 & 0.64 \\
CG & 0.71 & 0.56 & 0.64 & 1.00 \\
4 PPI BW & 1.00 & 0.64 & 0.59 & 0.88 \\
BL & 0.64 & 1.00 & 0.36 & 0.59 \\
WH & 0.59 & 0.36 & 1.00 & 0.48 \\
CG & 0.88 & 0.59 & 0.48 & 1.00 \\
\hline & & & &
\end{tabular}

NB: All the correlations were significant at $1 \%(\mathrm{P}<0.01)$.

All the correlation coefficients were found to be positive and moderate to high in magnitude and statistically significant $(\mathrm{P}<0.01)$. The magnitude of correlation ranged from 0.49 to 0.85 for age group one PPI, 0.18 to 0.77 in age group two PPI, 0.54 to 0.75 for age group three PPI and 0.36 to 0.88 in age group four PPI. Chest girth had correlation coefficient of greater magnitude with the body weight as compared to other two body measurements in almost all the age groups except the one PPI age group. Positive correlations of similar magnitude among body weight and body measurements have been reported in Mubende and Small East African Goat Breeds in Uganda (Jimmy et al., 2010), Central Highland and Woyto-Guji Goat Breeds of Ethiopia (Zergaw et al., 2017). Similar findings were also reported in KanniAdu goats (Thiruvankadan, 2005), in Malabari goats (Alex et al., 2010), in Attapady Black goats 


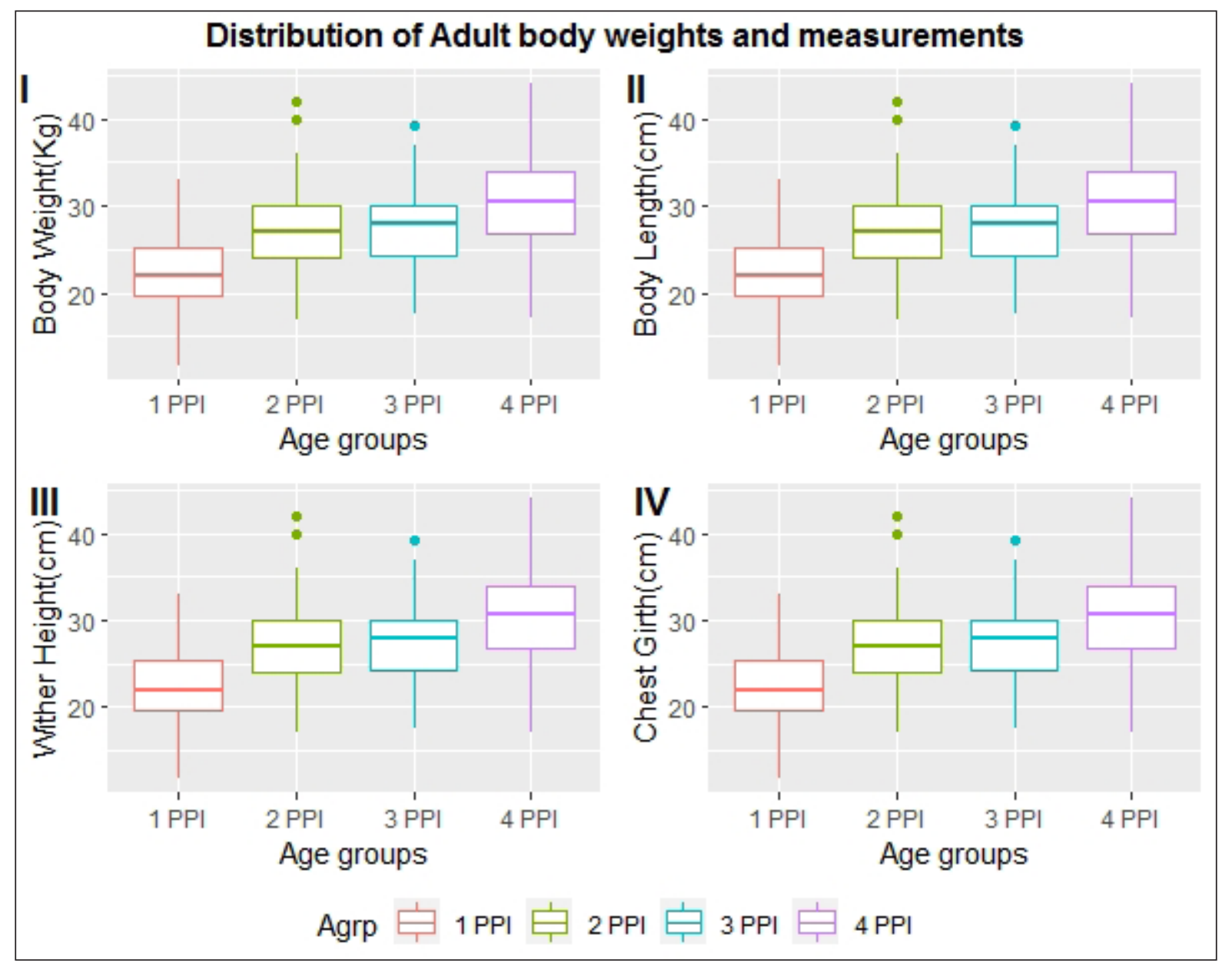

Fig. 1: Age group-wise box plot of adult body weight and body measurements of Ganjam goats

(Raja et al., 2015) and in Maefur goats (Berhe, 2017). The moderate to high correlation of the body weight with body measurements indicated that reliable prediction of bodyweight is possible from body measurements.

\section{Prediction equations from Single predictors}

Table 3 details the prediction equations from single body measurement as predictor variables, the p-values, R square, Root Mean Squares Error (RMSE) or residual standard error. All the models developed with each of the three body measurements were found to be statistically highly significant $(\mathrm{P}<0.01)$ with the $\mathrm{R}^{2}$ value ranging from 13 percent to 77 percent across age groups. It indicated that all the three predictor variables had considerable predictive value. The regression equation of the chest girth on body weight for age group 4 PPI had the highest coefficient of determination of 77 percent followed by the equations developed from body length ( 72 percent) at the age group one PPI. Body length was the best single predictor for body weight in the one pair incisor (1 PPI) age group accounting for 72 percent variability of body weight at one PPI group. Chest girth accounted for maximum variation in the body weight as evident from the $\mathrm{R}^{2}$ value obtained for age group 2 PPI, 3 PPI and 4 PPI age group. The present finding is in agreement with the observations made by Topal et al. (2003), Seifemichael et al. (2014), Chitra et al. (2012), Raja et al. (2015) and Habib et al. (2019). The chest girth seemed to have a greater influence on body weight as it is indicator of the body mass content in terms of bones, muscles, major internal organs as suggested by Mayaka et al. (1995). 
Table 3: Prediction equation of Body weight from each of the body measurements for different age groups (1 PPI to 4 PPI) and statistical parameters for fitted regressions

\begin{tabular}{|c|c|c|c|c|c|}
\hline Age Group & $\mathbf{N}$ & Regression equation & p-value & $\mathbf{R}^{2}$ & Sigma (RMSE) \\
\hline \multirow[t]{3}{*}{$1 \mathrm{PPI}$} & 269 & $-9.99+0.51 * \mathrm{BL}$ & $<0.001$ & 0.72 & 2.25 \\
\hline & & $-7.91+0.45^{*} \mathrm{WH}$ & $<0.001$ & 0.48 & 3.11 \\
\hline & & $-19.50+0.61 * \mathrm{CG}$ & $<0.001$ & 0.60 & 2.74 \\
\hline \multirow[t]{3}{*}{2 PPI } & 262 & $-20+0.71 * \mathrm{BL}$ & $<0.001$ & 0.57 & 2.95 \\
\hline & & $8.82+0.27 * \mathrm{WH}$ & $<0.001$ & 0.13 & 4.22 \\
\hline & & $-17.26+0.62 * \mathrm{CG}$ & $<0.001$ & 0.59 & 2.90 \\
\hline \multirow[t]{3}{*}{3 PPI } & 237 & $-18.81+0.68^{*} \mathrm{BL}$ & $<0.001$ & 0.57 & 2.66 \\
\hline & & $-0.25+0.39 * \mathrm{WH}$ & $<0.001$ & 0.29 & 3.44 \\
\hline & & $-12.88+0.56 * \mathrm{CG}$ & $<0.001$ & 0.51 & 2.85 \\
\hline \multirow[t]{3}{*}{4 PPI } & 246 & $-8.23+0.55 * \mathrm{BL}$ & $<0.001$ & 0.41 & 3.72 \\
\hline & & $-7.35+0.53 * \mathrm{WH}$ & $<0.001$ & 0.35 & 3.92 \\
\hline & & $-22.38+0.69 * \mathrm{CG}$ & $<0.001$ & 0.77 & 2.32 \\
\hline
\end{tabular}

Table 4: Prediction equation of Body weight from taking two predictors (body measurements) for different age groups.

\begin{tabular}{|c|c|c|c|c|c|}
\hline Age Group & $\mathbf{N}$ & Regression equation & p-value & Adj. $R^{2}$ & $\begin{array}{l}\text { Sigma } \\
\text { (RMSE) }\end{array}$ \\
\hline \multirow[t]{3}{*}{1 PPI } & 269 & $-15.75+0.41 * \mathrm{BL}+0.18 * \mathrm{WH}$ & $<0.001$ & 0.77 & 2.05 \\
\hline & & $-26.47+0.27 * \mathrm{WH}+0.45 * \mathrm{CG}$ & $<0.001$ & 0.72 & 2.27 \\
\hline & & $-19.59+0.37 * \mathrm{BL}+0.27 * \mathrm{CG}$ & $<0.001$ & 0.78 & 1.99 \\
\hline \multirow[t]{3}{*}{2 PPI } & 262 & $-29.30+0.67 * \mathrm{BL}+0.17 * \mathrm{WH}$ & $<0.001$ & 0.63 & 2.76 \\
\hline & & $-17.97+0.02 * \mathrm{WH}+0.6 * \mathrm{CG}$ & $<0.001$ & 0.58 & 2.90 \\
\hline & & $-34.82+0.48 * \mathrm{BL}+0.42 * \mathrm{CG}$ & $<0.001$ & 0.79 & 2.08 \\
\hline \multirow[t]{3}{*}{3 PPI } & 237 & $--21.65+0.60 * \mathrm{BL}+0.12 * \mathrm{WH}$ & $<0.001$ & 0.59 & 2.62 \\
\hline & & $-14.98+0.1 * \mathrm{WH}+0.49 * \mathrm{CG}$ & $<0.001$ & 0.52 & 2.83 \\
\hline & & $-28.13+0.47 * \mathrm{BL}+0.33 * \mathrm{CG}$ & $<0.001$ & 0.69 & 2.26 \\
\hline \multirow[t]{3}{*}{4 PPI } & 246 & $-25.65+0.43 * \mathrm{BL}+0.37 * \mathrm{WH}$ & $<0.001$ & 0.55 & 3.23 \\
\hline & & $-29.94+0.19 * \mathrm{WH}+0.6 * \mathrm{CG}$ & $<0.001$ & 0.80 & 2.15 \\
\hline & & $-26.89+0.16 * \mathrm{BL}+0.60 * \mathrm{CG}$ & $<0.001$ & 0.79 & 2.22 \\
\hline
\end{tabular}

\section{Prediction equations with multiple predictors}

The detailed regression output by taking two predictor variables and three predictor variables are presented in Table 4 and Table 5 respectively. It is tedious to take all possible combinations of predictor variables to get the best regression equation for prediction after taking into account the adjusted $\mathrm{R}^{2}$, root mean square error (RMSE) or residual standard error, the p-value of the model fit, AIC and BIC value of the model fit. In the two predictor variable combination, body length and chest girth combination had the highest adjusted $\mathrm{R}^{2}$ value of 78,79 and 69 percent, respectively for one PPI, two PPI and three PPI age groups, respectively. A step-wise regression method executed by SAS software resulted in selection of the bestfitted regression equation for each of the age groups. The best-fitted equations were-23.68 $+0.29 * \mathrm{BL}+0.16 * \mathrm{WH}$ $+0.25 * \mathrm{CG}$ for 1 PPI age group, the equation: $-34.82+$ $0.48 * \mathrm{BL}+0.42 * \mathrm{CG}$ for age group $2 \mathrm{PPI}$, the equation: $-28.13+0.47 * \mathrm{BL}+0.33 * \mathrm{CG}$ for age group 3 PPI and the equation: $-33.33+0.14 * \mathrm{BL}+0.18 * \mathrm{WH}+0.54 * \mathrm{CG}$ for age group 4 PPI. These equations had adjusted $\mathrm{R}^{2}$ value of $0.82,0.79,0.69$ and 0.82 for 1 PPI, 2 PPI, 3 PPI and 4 PPI, respectively. The best-fitted regression equation for age group 1 PPI had all the predictor variables as all the predictor variables remained significant $(\mathrm{P}<0.05)$ in the equation. But for the age group 2 PPI and 3 PPI the variable got dropped from the best-fitted equation as it was no more significant $(\mathrm{P}>0.05)$. Its addition to the regression had negligible effect on the improvement on the $\mathrm{R}^{2}$ value. For the best fitted equation for the age group 4 PPI all the 
西

Karna et al.

Table 5: Prediction equation of Body weight from taking all predictors (body measurements) for different age groups

\begin{tabular}{llllr}
\hline Age Group & $\mathbf{N}$ & Regression equation & p-value & $\begin{array}{l}\text { Adj.R } \\
\text { (RMSE) }\end{array}$ \\
\hline 1 PPI & 269 & $-23.68+0.29 * \mathrm{BL}+0.16 * \mathrm{WH}+0.25 * \mathrm{CG}$ & $<0.001$ & 0.82 \\
2 PPI & 262 & $-36.13+0.48 * \mathrm{BL}+0.04 * \mathrm{WH}+0.4 * \mathrm{CG}$ & $<0.001$ & 0.79 \\
3 PPI & 237 & $-27.82+0.48 * \mathrm{BL}-0.03 * \mathrm{WH}+0.35 * \mathrm{CG}$ & $<0.001$ & 0.69 \\
4 PPI & 246 & $-33.33+0.14 * \mathrm{BL}+0.18 * \mathrm{WH}+0.54 * \mathrm{CG}$ & $<0.001$ & 2.07 \\
\hline
\end{tabular}

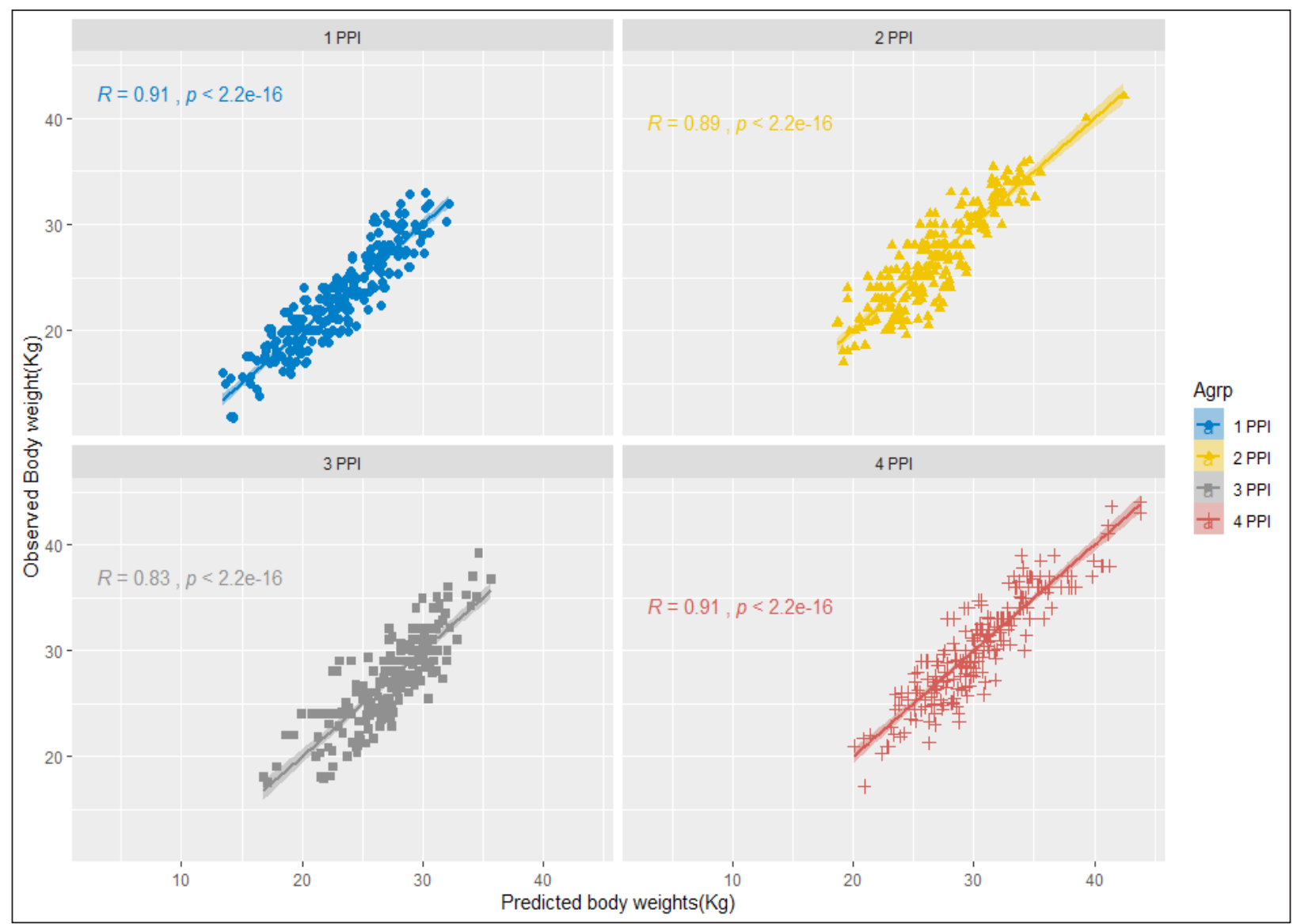

Fig. 2: Correlation of the Observed body weight with the predicted body weight from best fitted regression equation

three predictor variables were included. The mean absolute error (MAE) estimated using the best-fitted equation for body weights were calculated to be $1.50 \pm 0.07,1.64 \pm 0.08$, $1.83 \pm 0.09$ and $1.62 \pm 0.09 \mathrm{~kg}$ for age group 1 PPI to 4 PPI respectively. The mean absolute percentage error (MAPE) using the best fitted regression equations were $6.93 \pm 0.33$, $6.38 \pm 0.33,6.96 \pm 0.35$ and $5.49 \pm 0.31$ percent for age group 1 PPI to 4 PPI respectively. The correlation of the observed body weight with the predicted body weights were $0.91,0.83,0.89$ and 0.91 for 1 PPI, 2 PPI, 3 PPI and
4PPI age groups respectively that indicated a substantial accuracy of prediction as elucidated in the Fig. 2.

The body length was the principal predictor for the 1 PPI age group whereas the chest girth was the dominant predictor variable among the three linear body measurements for the rest three age groups. However, the other two variables contributed significantly for determining the variation in the body weight to justify their inclusion in the models. The present findings are in agreement with the earlier reports made by Jimmy et al. (2010) in adult Mubende 
and small East African goat breeds of Uganda, Chitra et al. (2012) in adult Malabari goats, Seifemichael et al. (2014) in Afar goats of Ethiopia, Berhe (2017) and Habib et al. (2019) in Black Bengal goats and Hopker et al. (2019) in crossbred Assamese goats.

\section{CONCLUSION}

The mean body weight of Ganjam goats ranged from 22.51 $\mathrm{Kg}$ in one pair permanent incisor age group to $30.60 \mathrm{Kg}$ in four pair permanent incisor age group. Highly significant, $(\mathrm{P}<0.001)$ moderate to high correlation of live weight with the body length, wither height and chest girth was observed in all the four age groups studied. Chest girth is the most important predictor of the live weight. However, the other two measurements can be used in combination with the chest girth to predict the body weight more accurately. The prediction equation developed can be used in the absence of weighing scale to predict the body weight with fair accuracy ( 5 to 7 percent error) in the field condition.

\section{ACKNOWLEDGEMENTS}

Authors are thankful to All India Coordinated Research Project on goat improvement, (ICAR, New Delhi) for providing financial support to carry out this research.

\section{REFERENCES}

Anonymous, 2019. Basic Animal Husbandry Statistics. Government of India, Ministries of Fisheries, Animal Husbandry and Dairying, Krishi Bhawan, New Delhi.

Alex, R., Raghavan, K.C. and Mercey, K.A. 2010. Prediction of body weight of Malabari goats from body measurements under field conditions. J. Vet. Anim. Sci., 41: 21-27.

Berhe, W.G. 2017. Relationship and Prediction of body weight from morphometric traits in Maefur goat population in Tigray, northern Ethiopia. J. Biom. Biostat., 8(5): 370-376.

Chitra, R., Rajendran, S., Prasanna, D. and Kirubakaran A. 2012. Prediction of body weight using appropriate regression model in adult female Malabari goat. Vet World, 5(7): 409-11.

Das, N. and Sharma, A.K. 1994. Growth performance of Black Bengal goats. Cheiron, 23(2): 66-78.

Habib, M.A., Akhtar, A., Bhuiyan, A.K.F.H., Choudhury, M.P. and Afroz1, M.F. 2019. Biometrical relationship between body weight and body measurements of Black Bengal Goat (BBG). Curr. J. Appl. Sci. Tech., 35(2): 1-7.
Hopker, A., MacKay, J., Pandey, N., Hopker, S., Saikia, R., Pegu, B., Saikia, D., Minor, M., Goswami, J., Marsland, R. and Sargison, N. 2019. Weight estimation in native crossbred Assamese goats. Livest. Res. Rural Dev. Volume 31, Article \#162. Retrieved May 26, 2020 from http://www.lrrd.org/ $\operatorname{lrrd31/10/ahopk31162.html}$

Jimmy, S., David, M., Donald, K.R. and Dennis, M. 2010. Variability in body morphometric measurements and their application in predicting live body weight of Mubende and Small East African goat breeds in Uganda. Middle-East $J$. Sci. Res., 5(2): 98-105.

Karna, D.K., Acharya, A.P., Das, B.C., Nayak, G.D. and Dibyadarshini, M.R. 2020. Morphometry of Ganjam goats of Odisha and age specific body weight prediction from linear body measurements. The Pharma Innov. J., SP- 9(4): 171175 .

Kuralkar, S. V., Verma, N. K., Kharkar, K. and Kuralkar, P. 2013. Berari goats: Characterization, management, performance and population status. Indian J. Anim. Sci., 83(12): 12921298.

Mayaka, T.D., Tchoumboue, J., Manjeli, Y. andTeguia, A. 1995. Estimation of live weight in West African Dwarf goats from heart girth measurement. Trop. Anim. Health Prod., 28: 126128 .

R Core Team. 2020. R: A language and environment for statistical computing. R Foundation for Statistical Computing, Vienna, Austria. [URL http://www.R-project.org/].

Raja, T.V., Venkatachalapathy, R.T., Kannan, A. and Bindu, K.A. 2015. Determination of best-fitted regression model for prediction of body weight in Attappady black goats. Int. $J$. Agric. Sci., 5(3): 423-457.

Rao, P.K., Dash, S.K., Singh, M.K., Rai, B. and Singh, N.P. 2009. Ganjam goats of Orissa and its management practices. Indian J. Small Rum., 15: 44-50.

SAS (Statistical Analysis System).2009. SAS for windows, Release 9.3 SAS Institute, Inc., Cary, NC, USA.

Seifemichael, M., Kefelegn, K., Negassi, A. and Banerjee, A.K. 2014. Variability in linear body measurements and their application in predicting body weight of Afar Goats in Ethiopia. Int. J. Interdiscip. Multidiscip. Stud., 1(4): 17-25.

Thiruvenkadan, A.K. 2005. Determination of best fitted regression model for estimation of body weight in KanniAdu kids under farmer's management system. Livest. Res. Rural Dev., 17(7): 76-87.

Topal, M., Yildiz, N., Esenbuga, N., Aksakal, V., Macit, M. and Ozdemir, M. 2003. Determination of best fitted regression model for estimation of body weight in Awassi sheep. $J$. Appl. Anim. Res., 23: 201-208. 
Topal, M. and Boulkbasi, S.C. 2008. Comparison of nonlinear growth curve models in broiler chickens. J. Appl. Anim. Res., 34: $149-152$.

Verma, N.K., Dixit, S.P., Dangi, P.S., Aggarwal, K.S. and Joshi, B.K. 2009. Malabari goats: Characterization, management,performance and genetic variability. Indian $J$. Anim. Sci., 79(8): 813-18.
Verma, N.K., Dixit S.P., Aggarwal, R.A.K., Dangi, P.S. and Joshi, B.K. 2010. Phenotypic and genetic characterization of Sangamneri goat breed. Indian J. Anim. Sci., 80(11): 110914.

Zergaw, N., Dessie, T. and Kebede, K. 2017. Using morphometric traits for live body weight estimation and multivariate analysis in Central Highland and Woyto-Guji Goat Breeds, Ethiopia. African J. Agri. Res., 12(15): 1326-1331. 